\title{
ANOMALIA DA VIA BILIAR EXTRA-HEPÁTICA
}

\author{
BILIARY DUCTAL ANOMALY
}

\author{
Edson Yuzur Yasojima, TCBC-PA ${ }^{1}$ \\ Pedro Antônio Mufarrej Hage, TCBC-PA ${ }^{2}$ \\ Tárik Olívar de Nunes Valente ${ }^{3}$
}

\section{INTRODUÇÃO}

O grande número de variações anatômicas das vias biliares é sem dúvida um desafio aos cirurgiões gerais que freqüentemente se deparam com elas. As mais comuns estão relacionadas com a posição e a implantação do ducto cístico nas vias biliares extra-hepáticas e com o aparecimento de ductos biliares extra-hepáticos acessórios paralelos à vesícula biliar ${ }^{1}$.

Além destas, há aquelas extremamente raras, pouco descritas na literatura, e que, eventualmente, quando se apresentam, podem causar embaraços ao cirurgião no curso da cirurgia biliar ${ }^{1}$.

Neste trabalho descrevemos um caso de anomalia congênita das vias biliares extra-hepáticas, caracterizada por ausência de ducto colédoco, com implantação baixa dos ductos hepáticos direito e esquerdo, e implantação do ducto cístico no ducto hepático direito.

\section{RELATO DO CASO}

Paciente do sexo feminino, 58 anos de idade, referia que há dois meses após colecistectomia, passou a apresentar desconforto abdominal, náuseas, icterícia, colúria, calafrios, febre $\left(38^{\circ} \mathrm{C}\right)$. Os valores de bilirrubina e frações demonstraram um aumento progressivo desde a data da cirurgia, bem como de fosfatase alcalina e leucócitos.

No dia 18 de maio de 1999 a paciente foi internada no Hospital Amazônia da Beneficência Nipo-Brasileira da Amazônia para a realização de colangiopancreatografia retrógrada endoscópica e possível esfincterotomia.

Durante a realização da CPRE, ainda na duodenoscopia, foi observada papila de Váter em parede medial da segunda porção duodenal, de aspecto anatômico. Após sua cateterização percebeu-se drenagem de pequena quantidade de secreção purulenta proveniente das vias biliares (Figura 1).

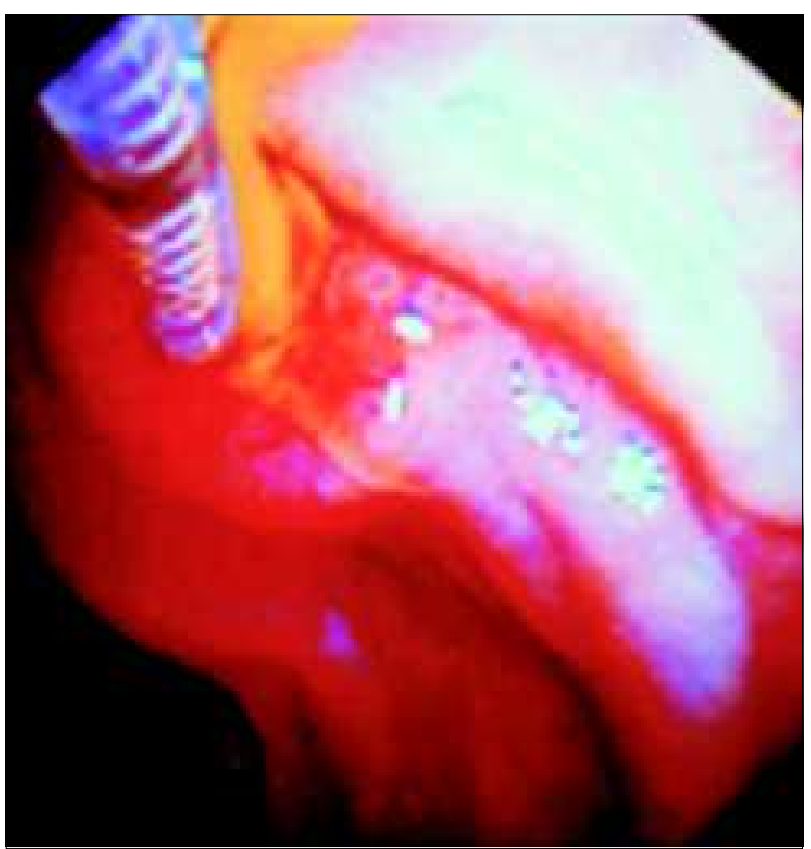

Figura 1 - Cateterização da papila de Váter e drenagem de secreção purulenta.

A CPRE revelou opacificação simultânea do ducto de Wirsung e vias biliares, estas apresentando uma duplicidade de canal biliar extra-hepático, correspondendo a ducto hepático direito $(1,3 \mathrm{~cm})$ e ducto hepático esquerdo $(1,0 \mathrm{~cm})$, ambos com inserção baixa, próximo à parede duodenal com o diâmetro aumentado e com dificuldade esvaziamento para o duodeno. Observou-se o coto cístico implantado no ducto biliar direito (Figura 2). Realizada esfincterotomia endoscópica.

A colangioressonância confirmou subestenose biliar no seu trajeto intrapancreático, além da variação anatômica das vias biliares extra-hepáticas (Figura 3).

1. Professor Colaborador do Departamento de Medicina Integrada I - UEPA. Cirurgião do Aparelho Digestivo do Hospital da Beneficência Nipo-Brasileira da Amazônia.

2. Cirurgião do Aparelho Digestivo do Hospital da Beneficência Nipo-Brasileira da Amazônia.

3. Graduando do Curso de Medicina da Universidade do Estado do Pará

Recebido em 18/10/2000

Aceito para publicação em 09/10/2001

Trabalho realizado no Serviço de Cirurgia Geral do Hospital da Beneficência Nipo-Brasileira da Amazônia - Belém-PA. 


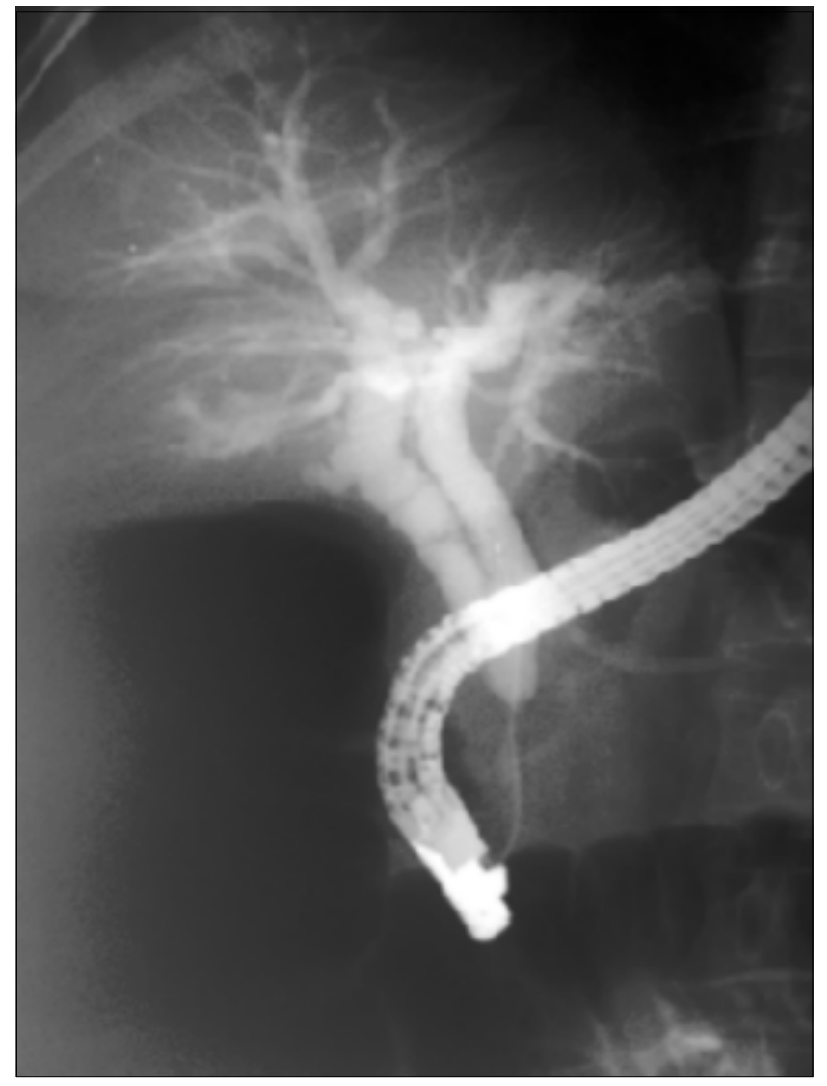

Figura 2-CPRE: ductos hepáticos direito e esquerdo longos e coto do ducto cístico no ducto hepático direito.

A paciente apresentou boa evolução clínica da icterícia obstrutiva após a papilotomia.

\section{DISCUSSÃO}

A disposição da via biliar tida como normal é composta por ductos hepáticos direito e esquerdo de confluência alta, pela presença de um ducto hepático comum de aproximadamente 2 a $3 \mathrm{~cm}$ de comprimento e pela inserção do ducto cístico em ângulo agudo, originando o ducto colédoco com cerca de $3 \mathrm{~cm}$ ou mais de comprimento. No entanto, estas características anatômicas foram encontradas em apenas $35 \%$ dos casos em trabalho realizado com 787 pacientes no Hospital Pirovano, Buenos Aires, Argentina $^{2}$.

O ducto cístico é o que sofre maior número de variações no que diz respeito ao seu comprimento, diâmetro e desembocadura. Já a via biliar principal, dividida em ducto hepático comum e ducto colédoco, apresenta variações em menor escala, entretanto, significativas ${ }^{2}$.

O ducto hepático comum apresenta comprimento variável e só não está presente quando da desembocadura do ducto cístico no nível da confluência do ducto hepático direito e esquerdo ${ }^{2}$.

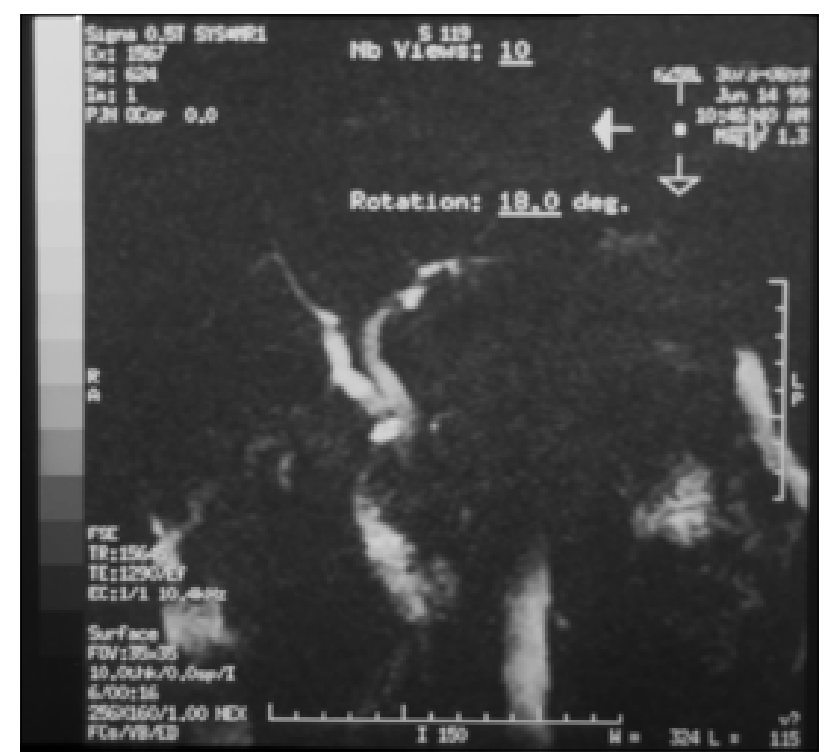

Figura 3 - Colangiorressonância de abdome superior.

Uma variação da via biliar principal e que apresenta importância cirúrgica é a formação extra-hepática baixa, quando a confluência dos ductos hepáticos direito e esquerdo ocorre próximo ao duodeno. Nesses casos, se o indivíduo possuir um ducto cístico curto, há grandes possibilidades de confundir-se o ducto hepático direito com o ducto cístico e o ducto hepático esquerdo com o ducto colédoco ${ }^{2}$.

Este tipo de variação é a que relatamos neste trabalho, procurando demonstrar que nestes casos o indivíduo apresenta uma ausência do ducto colédoco, pois a definição anatômica de ducto colédoco é a inserção do ducto cístico, no ducto hepático comum, pela direita e em ângulo agudo ${ }^{3-5}$.

Como no caso em questão o ducto cístico implanta-se no ducto hepático direito e não no ducto hepático comum, a variação anatômica gira em torno de uma ausência de ducto colédoco, com confluência baixa de ductos hepáticos direito e esquerdo. A errônea interpretação desta anatomia no momento de uma cirurgia nessa região poderia ser a origem de uma série de complicações e até mesmo do óbito do paciente ${ }^{3,4}$.

O ducto colédoco é o segmento com menor número de variações na via biliar principal, as quais detêm-se mais no ponto de desembocadura do ducto cístico e na sua implantação no duodeno ${ }^{3,4}$.

A freqüência cada vez maior de cirurgias realizadas com mínimas incisões e a grande expansão da videolaparoscopia torna o conhecimento anatômico das vias biliares e de suas variações anatômicas um fator importante para o sucesso de cirurgias nessa região, uma vez que essas técnicas tornam mais trabalhosas ou até mesmo dificultam a dissecção das vias biliares, o que pode aumentar o risco de lesões ${ }^{4}$. 


\begin{abstract}
We show an anatomical modification of extrahepatic biliary ducts in a fifty-eight years old female who presented right hipocondric pain, jaundice and fever two months after cholecystectomy. The patient underwent ERCP wich showed an anatomical modification that consists in an union of the right and left hepatic ducts, with insertion into the cystic duct, right hepatic duct, being a choledochus agenesis.
\end{abstract}

Key Words: Agenesy; Biliary anomalies; Common bile duct.

\title{
REFERÊNCIAS
}

1. Behara N, Jiron A, Cabeza L et al. Anomalías de las vías biliares extrahepáticas: descripción de un caso com ausencia de colédoco y drenaje del conducto hepático común en la vesicula biliar. Rev. Soc. Méd - Qui. Hosp. Emerg. Perez de León 1985; 20(1): 61-70.

2. Ciardullo M, Sisco P, Bargnia A et al. Importancia quirúrgica de las variaciones anatómicas del pedículo hepático. Rev. Argent. Cir. 1985; 48(3/4): 138-42.

3. Berci G. Biliary ductal anatomy and anomalies. Surgical Clinics of North America 1992; 72(5): 1069-75.

4. Araújo IV, Lopes RLC, Petroianu A et al. Variações anatômicas da via biliar principal em estudos radiológicos. An. Paul. Med. Cir.1995; 122(1): 18-21.
5. Moore KL. Anatomia orientada para a clínica. 3.ed. Rio de Janeiro, Guanabara Koogan, 1994.

Endereço para correspondência:

Edson Yuzur Yasojima

Tv. 9 de Janeiro, 1267 - São Braz

66060-370 — Belém-PA 